\title{
Exploring the components of brand equity amid declining ticket sales in Major League Baseball
}

\author{
Adam C. Merkle ${ }^{1}$ (D) Catherine Hessick $^{1}$ (D) $\cdot$ Britton R. Leggett ${ }^{1} \cdot$ Larry Goehrig $^{1} \cdot$ Kenneth $^{\prime}$ Connor $^{1}$
}

Received: 30 November 2019 / Revised: 1 May 2020 / Accepted: 3 July 2020 / Published online: 21 July 2020

(c) Springer Nature Limited 2020

\begin{abstract}
Ticket sales for Major League Baseball (MLB) games are decreasing annually, yet baseball fans have increased team interest and following in other ways. Instead of following from the stands or on television fans are choosing to follow, for example, via social media. The emerging unified theory of brand equity offers a framework to examine the mediating role of attendance and local television and the moderating role of Twitter followers on the relationships between MLB marketing assets (MA) and team financial performance. Publicly available secondary data are analyzed with PLS-SEM. The results indicate attendance and local TV partially mediate the relationship between non-seasonal MA and team financial performance, whereas attendance and local TV fully mediate the relationship between in-season MA and team financial performance. Furthermore, the number of Twitter followers for each MLB team moderates various relationships within the MLB brand equity research model. Findings suggest MLB sales and marketing professionals should design ticket sales initiatives that not only promote attendance in the short-term but, more importantly, build upon non-seasonal sources of team brand equity for the long-term.
\end{abstract}

Keywords Sales $\cdot$ Analytics $\cdot$ Brand equity $\cdot$ Social media $\cdot$ Structural equation modeling $\cdot$ Sports marketing

\section{Introduction}

Picture yourself sitting down in a favorite chair with a cold beverage on a beautiful, sunny day without a cloud in sight. Yet when turning on the television to watch your favorite team, you notice something odd. As the cameras pan across the seats in the ballpark, there is no roaring crowd, and nearly half the stadium is empty. If not at the game, where is everyone? Have they, like you, chosen to watch the game in the relative comfort of their residence? Unfortunately, many sports teams, particularly in Major League Baseball (MLB), are asking the same question. Where have all the fans gone?

Despite the efforts of sales and marketing professionals, ticket sales and game attendance numbers fell for the fourth consecutive year leading sports pundits and long-term

Electronic supplementary material The online version of this article (https://doi.org/10.1057/s41270-020-00083-7) contains supplementary material, which is available to authorized users.

Adam C. Merkle

acm1821@jagmail.southalabama.edu

1 Mitchell College of Business, University of South Alabama, Mobile, AL 36688, USA baseball loyalists to wonder if we are entering an early stage decline of the sport (deMause 2019; Kelly 2019; Love 2019). One journalist recently suggested the attendance decrease may be a result of a culmination of factors, including ticket prices, a sophisticated secondary ticket market, and the poor performances of teams (Brown 2019). This study seeks to uncover the practical, marketing-related antecedents of game attendance and local television (TV) viewership within the unified theory of brand equity (Davcik et al. 2015). Specifically, we examine marketing assets for MLB teams, their relationship with stakeholders, and the relative influence of those marketing assets, game attendance, and local TV viewership on team financial performance. These relationships may have key implications for the sales and marketing efforts of MLB teams. For example, if declining ticket sales are more than offset by other sources of rising revenue, then sales and marketing teams need not be concerned with small ticket sales decreases. However, if declining ticket sales have a large impact on team revenue or are the result of an eroding fan base, more effort should be placed on driving game attendance. A marketing analytics approach may be helpful in taking the first step to explore these relationships.

Organizations are increasingly making decisions based on an in-depth statistical analysis of data (Erevelles et al. 2016). 
This journal defines marketing analytics as "the study of data and modeling tools used to address marketing resource and customer-related business decisions" (Iacobucci et al. 2019, p. 155). Marketing analytics offers hope that, in the future, we can better understand and perhaps predict trends through the power of data analysis (Wedel and Kannan 2016). In this study, we take a marketing analytics approach using only publicly available secondary data to organize and evaluate the variables of interest.

The findings contribute to the marketing literature in three ways. First, we show that a data-driven marketing analytics approach can be useful in the ongoing development of the unified theory of brand equity. Second, we present and test an empirical model of MLB brand equity and establish the relative influence of non-seasonal marketing assets (i.e., franchise age, number of Hall of Famers, metro population, etc.) and in-season marketing assets (i.e., at-bats, runs, hits, etc.) on attendance, local TV viewership, and team financial performance. We find that non-seasonal marketing assets are more influential in every relationship. Third, we find evidence that alternative marketing assets, such as Twitter, are associated with changes in multiple relationships within the brand equity model. One change involves the weakening of the relationship between non-seasonal MA and attendance, effectively resulting in a lower rate of increases in game attendance for those teams with higher numbers of Twitter followers.

\section{Theoretical background}

Academics and practitioners alike understand the value of a well-known brand to the bottom line. Given the longevity of MLB teams, such as the Chicago Cubs, New York Yankees, and Boston Red Sox, brand equity plays a vital role as an intangible asset in the organization. Brand equity has traditionally been examined via one of three perspectives, namely company- based (i.e., marketing assets), customer-based (i.e., stakeholder value), or financially based (i.e., financial performance) (Keller and Lehmann 2006). First, marketing assets, both tangible and intangible, help drive customer value and deliver advantages for the firm, thus growing brand equity (Srivastava et al. 2001). Yoo et al. (2000) noted that brand equity could be affected by any marketing endeavor, such as advertising, price promotions, or distribution, since each new marketing action only adds to the organization's previous investments in the brand. Therefore, it is important to use all available marketing assets wisely as to not erode brand equity.

Second, the customer-based perspective of brand equity, first introduced by Aaker (1991), focuses on value creation for both the firm and the customer. Recent research has broadened the customer-based perspective to include value creation for all parties, rather than just customers at the expense of shareholders (Freeman 1994, Jones 2005, Laplume et al. 2008, Hult et al. 2011). Labeled stakeholder value, this approach may help lay the foundation for longterm growth. One avenue to increase stakeholder value is through the strength of the brand. Research has shown the multitude of benefits from having a strong brand, such as brand awareness and recall (Johnson and Russo 1984; Kent and Allen 1994; Shamsollahi et al. 2017), inclusion in consideration sets (Lane and Jacobson 1995; Terech et al. 2009) and brand performance (Chaudhuri and Holbrook 2001; De Vries and Carlson 2014; Hoeffler and Keller 2003). Consequently, brand strength can help increase stakeholder value, thus increasing brand equity.

Lastly, financial-based brand equity focuses on the worth of the brand. Like any asset, brand equity's value influences decision making and subsequently affects the bottom line. Unfortunately, research on how brand equity is measured lacks consistency. Simon and Sullivan (1993) developed both a micro and macro approach for brand equity valuation using stock market values. The micro approach examines brand equity at the individual brand level to assess the impact specific marketing decisions have, whereas the macro approach evaluates at the firm level using an objective, mathematical formula. Other measures include price premium (Aaker 1996), customer lifetime value (Gupta and Lehmann 2006), and momentum accounting (Farquhar and Ijiri 1993). However, with each measure having its own advantages and drawbacks, relying on one measurement tool could result in a partial picture of the full value of the brand. Therefore, as Ambler and Barwise (1998) concluded, companies would be wise to use multiple measurements in conjunction with other brand equity measures, such as marketing assets, to obtain a truer value.

In the literature, brand equity is viewed differently depending on the chosen perspective. Recognizing this gap, Davcik et al. (2015) proposed the emergence of a unified theory where all three perspectives, company-based, customer-based, and financial-based, are collectively considered in evaluating brand equity. With each perspective potentially interacting with the others, the authors believe viewing brand equity through one perspective results in the loss of the full extent of interaction. Thus, brand equity should ideally be evaluated using all three perspectives. Davcik et al. (2015) are not alone in their beliefs, as additional research has supported the need for an expanded measure of brand equity (Chatzipanagiotou et al. 2016).

In this paper, we analyze MLB data involving measures of marketing assets, stakeholder value, and financial performance in the manner described by the emerging unified theory of brand equity. We distinguish between two marketing assets (MA), non-seasonal MA (e.g., city population, playoff history, hall of fame record), and in-season MA (e.g., team 
performance), and suggest that each underlying asset influences stakeholder value represented by game attendance and local TV viewership. It is known that MLB game attendance has declined in recent years (deMause 2019; Kelly 2019; Love 2019); however, there is a lack of research investigating why. Furthermore, the interaction between marketing assets, game attendance, and the effects on financial performance (e.g., revenue and valuation) have yet to be explored. Simultaneously analyzing the data across all three areas represented in the unified theory of brand equity will capture the interaction between each area. Based on our findings, we offer support for the emerging unified theory of brand equity, discuss implications associated with low attendance, and suggest how salespeople could further the goal of building team brand equity.

\section{Literature review and hypothesis development}

The unified theory of brand equity calls for a blended view of the brand equity mix involving the three primary relationships of marketing assets, stakeholder value, and firm value. Recent sports marketing studies have investigated company-based, customer-based, or financially based brand equity across numerous professional sports, including the national basketball association (NBA), major league soccer (MLS), and the national football league (NFL). However, these studies tend to focus on only one or two aspects of brand equity. For example, a study across six teams in the NBA provided evidence that a team's company-based marketing assets, called marketplace characteristics, influence measures of fan social identification leading to changes in customer-based brand equity (Watkins 2014). In MLS, a customer-based brand equity measure of brand association by fans included measures of teams' marketing assets such as on-field performance, team history, coaching, and management, among others (Biscaia et al. 2013). Lastly, a study investigating brand equity in the NFL offers evidence that teams' ability to construct new stadiums is an influential marketing asset related to revenue, which is a component of financial-based brand equity (Abreu and Spradley 2016).

This research, however, investigates a brand equity model in MLB according to the unified theory of brand equity. Below, we briefly discuss firm value, marketing assets, and stakeholder value as they relate to MLB. Firm value is reflected by team financial performance. Two primary marketing assets are identified as non-seasonal factors and in-season team performance. Two measures for assessing stakeholder value include game attendance and local TV viewership. Lastly, we evaluate the impact of Twitter followers as a key social media development within the brand equity model for MLB.

\section{Team financial performance}

Team financial performance is considered a subjective measure because it can be approached from various perspectives, including accounting measures or marketing measures. An accounting approach would involve measures of how well a team uses its assets, otherwise known as a return on assets. Marketing and sales professionals may focus instead on forward-looking metrics such as ticket sales revenue or financial valuations. These are marketing measures. Marketing measures are considered by some to be a more accurate picture of firm value because they are often less susceptible to accounting changes and manipulations (McGuire et al. 1988).

Financial performance is composed of numerous sources beyond ticket sales from game attendance. For example, television contracts, negotiated by each team, contribute a significant amount to revenue. According to Forbes (2019), the Yankees receive \$191 million and have a $20 \%$ equity stake in the network, bringing their annual revenue from television rights to $\$ 385$ million, whereas the Los Angeles Dodgers, with its equity stake, bring in \$334 million per year. Smaller markets, such as San Diego, also partake in revenue-generating television contracts as the Padres received $\$ 70$ million from television rights (Forbes 2019).

A second source of income is revenue sharing, stemming from the collective bargaining agreement between the players union and the owners. Revenue sharing resembles a redistribution tax to shift money from larger markets to smaller markets for Major League Baseball teams (Rockerbie and Easton 2018). Under the current collective bargaining agreement, each team contributes $34 \%$ of its revenue into a pool. The MLB divides the pool equally, and 1/30th goes back to each organization (Rockerbie and Easton 2018). In 2018 alone, each club received \$118 million, an amount greater than some teams' entire payroll. Thus, revenue sharing is a cost for large market teams and a revenue source for smaller markets. The significance of these revenue streams is such that Forbes regularly accounts for them at the team level in their reporting and analysis of valuations (Forbes 2019).

In the present study, team financial performance is a blended set of marketing measures and is the result of the overall effectiveness of marketing assets and measures of stakeholder value. This view aligns with other sportsrelated brand equity frameworks where ticket sales and TV contracts are specifically conceptualized as a consequence of brand equity (Kerr and Gladden 2008). However, ticket sales and TV contracts simultaneously reflect stakeholder value wherein greater numbers of spectators are an indication of increased value delivered to customers. Thus, team financial performance is the result of (1) the effectiveness 
of its use of marketing assets but also (2) reflects the level of stakeholder value delivered to its customers.

\section{Non-seasonal marketing assets}

Some sports team brand elements extend beyond the regular season in their ability to create excitement and increase brand equity. In this study, we consider several non-seasonal variables related to attendance, local TV viewership, and team financial performance. These variables include population, franchise (club) age, the frequency and quantity of playoff appearances, and the number of Hall of Fame members per team. First, population, derived from each team's Metropolitan Statistical Area (MSA), plays an essential role in baseball attendance since larger populations increase the number of potential customers (Bradbury 2019). To explain baseball attendance, Government and the Sports Business offered a multi-variable equation where factors, such as ticket sale prices, number of star players, and competition from other sports, are multiplied by population (Noll, 1973). When analyzing MLB attendance from 1969 to 1987, Baade and Tiehen (1990) concurred that the population could significantly influence many items including attendance with this statement, "though Noll's process of multiplication potentially creates a high level of multicollinearity, the fact remains that population merits inclusion while researching attendance."

Other variables, such as the number of playoff appearances, cumulative world series wins, and club age, reflect the history and prestige of a baseball club. We selected these variables as they can influence brand loyalty, which can, in turn, affect in-person viewing, at-home viewing, and financial performance. For example, the Chicago Cubs are known for their loyal fans who continuously support the team through merchandise purchases and game attendance, regardless of its performance (Bristow and Sebastian 2001). Zimmer (2014) examined World Series wins and found that "the average benefit of a playoff appearance afforded to MLB teams is an average increase in attendance of approximately 140,966" (Zimmer 2014, p.30).

We hypothesize these various elements can be combined in the formation of a non-seasonal marketing asset influencing attendance, local TV viewership, and team financial performance. Higher levels of population, playoff successes, and Hall of Fame caliber players will result in larger numbers of spectators at the ballpark and watching on television. Increased numbers of spectators will generate larger ticket sales. Higher sustained TV viewership levels will allow teams to increase the amount of revenue generated from their television contracts. We, therefore, hypothesize the following relationships:
H1a: Non-seasonal marketing assets are positively related to attendance.

H1b: Non-seasonal marketing assets are positively related to local TV viewership.

H1c: Non-seasonal marketing assets are positively related to team financial performance.

\section{In-season marketing assets}

On-the-field team performance can be broken into two categories, offense and defense. Which category of performance is more influential in driving stadium attendance and fan viewship? An econometric model recently validated certain measures of offense, including hometeam slugging percentage and runs per game, as statistically significant determinants of attendance (Lee 2018). While a team's defense is vital to winning games, home runs, fly balls, and RBIs generate excitement on the ballfield. Baseball teams that recognize the benefits of a productive offense likely view it as a beneficial marketing asset for ticket sales.

The implementation of the designated hitter rule offers an example of how an exciting team offense can improve the game viewing experience. In 1973, the American League adopted the designated hitter (DH) rule on the belief that increased offensive output would increase attendance (Domazlicky and Kerr 1990). Designated hitters allow a skilled batter to hit in the line-up instead of the pitcher, yet the pitcher is allowed to remain in the game during the defensive (pitching) cycle. The DH rule had two major implications. First, DHs are typically better hitters than National League pitchers who were required to bat, thus providing American League teams an advantage. Second, the DH may impact the opposing teams' pitching strategy, because the DH represents the potential for increased numbers of intentional walks, base hits, and home runs. In the seven years following the introduction of the $\mathrm{DH}$ rule, the American League experienced an increase in runs per game from 3.9 to 4.4 , producing an increase of $12.8 \%$ in runs per game over the seven years before the DH (Domazlicky and Kerr 1990). The National League, which did not introduce DH, saw a modest rise of just $1.2 \%$ over the same years (Domazlicky and Kerr 1990).

A productive offensive has been linked to positive attendance when measured over the course of an entire season (Tainsky 2008). During the steroid era, from the mid-' $90 \mathrm{~s}$ to the early 2000s, team offense became a central draw for MLB attendance as reflected by ticket price increases of $78 \%$, and attendance increases approaching $115 \%$ (Koslosky 2014). The exciting atmosphere created by extra-base hits and home-run titles resulted in higher levels of ballpark attendance, and also likely increased television viewership. 
By the end of the 2001 season, runs per game increased to 5.14 (Koslosky 2014). Moreover, others find that team offensive output has been a significant determinant for attendance since the inception of Major League Baseball (Ahn and Lee 2014).

When a team is having a successful season, that success is often attributed to increases in seasonal offensive output. An increase in offensive output (i.e., in-season marketing assets) can be measured in many ways such as singles, doubles, triples, sacrifice flys, home runs, total at-bats, and runs batted in or combined ratios like batting averages, on-base percentages, and slugging percentages (Ahn and Lee 2014; Lee 2018). Thus increases in seasonal offensive output are associated with increased fan attendance and television viewership. Increases in attendance and television viewership will likely generate increases in team financial performance via higher ticket sales and the potential for increased advertising demand. For these reasons, we suggest that seasonal offensive output represents a distinct in-season marketing asset that is positively related to other elements of MLB brand equity as hypothesized below:

H2a: In-season marketing assets are positively related to attendance.

H2b: In-season marketing assets are positively related to local TV viewership.

H3c: In-season marketing assets are positively related to team financial performance.

\section{Attendance}

In this study, we assess stakeholder value according to various measures of game attendance and local TV viewership. Attendance is an appropriate way to evaluate stakeholder value because it captures the willingness of fans to pay and travel, an atmosphere of excitement for players to enjoy while competing, and a financial return to ownership in the form of sales. Though MLB attendance has continually declined in recent years, detailed information about the timing, universality, and proportion of the trend is scarce. Likewise, predictive research about the potential consequences of the attendance decline is difficult to find. Furthermore, from the perspective of club revenue and financials, it is unclear whether the downward trend in attendance is a problem.

Another complication arises in that the proportion of attendance increase, or decline, is not regularly reported in studies related to the effects of MLB attendance (Lemke et al. 2010). Trends show the current attendance decline began around 2012. Prior to that year, MLB attendance was reportedly rising (Beckman et al. 2012). However, from the perspective of the business of baseball, we need to begin to understand whether and how strongly attendance increases (decreases) are related to revenue and valuation changes. For example, if changes in club revenue are greater (lesser) than an attendance increase (decrease), this could indicate that attendance is becoming a less critical issue for the sport.

Attendance is primarily driven by key non-seasonal and in-season marketing assets. Regular baseball enthusiasts may respond to non-seasonal marketing assets resulting from their brand loyalty or social habits and choose to visit the ballpark. Newer fans however, may instead respond to inseason marketing assets, for example when their local team is having a successful year competing for a division title or heading toward playoff competition. Whether responding to non-seasonal MA or in-season MA, fans choose to attend a game and receive some level of stakeholder value. When fans spend money on tickets, they generate firm value to the ball club. Ticket sales are not the only source of revenue generated by attendance. Fans also purchase concessions and memorabilia. Some portion of gate sales, concessions, and memorabilia are retained by local authorities and the remaining amounts are sent to the team. For these reasons, a portion of team revenue generated by the effectiveness of a team's marketing assets is indirectly paid to the team via ticket sales. Whereas other portions of revenue from attendance are directly related to additional sales that occur during game attendance. Therefore, as marketing assets effectively drive attendance increases, we expect to observe a corresponding increase in team revenues and hypothesize:

H3a: Attendance is positively related to team financials.

H3b: Attendance partially mediates the positive relationship between non-seasonal marketing assets and team financials.

H3c: Attendance partially mediates the positive relationship between in-season marketing assets and team financials.

\section{Local TV}

Within the theoretical framework of the unified theory of brand equity, local TV viewership is another measure of stakeholder value. Local TV viewership represents an alternative to game attendance by solving fan barriers such as limited stadium capacity and geographic boundaries. Regional sports networks (RSN's) obtain exclusive contract rights to show local MLB games on their networks (Kunz 2017). These contracts allow RSN's to earn additional revenue through exclusive advertising sales with some portion of that revenue offsetting the cost of the contract paid by RSN's to the local MLB team. Overall TV viewership in MLB and other professional sports was still growing through 2016 (Chung et al. 2016). However, MLB has seen a continued recent decline in total local 
TV viewership starting in 2018, according to Nielsen ratings data (Forbes 2019). RSN contracts generally include a fixed and variable amount and may last for many years (Kunz 2017). As such, there is a floor on any revenue decrease to the local MLB team if local TV viewership declines. However, there may be some ability for a team to increase local TV revenue to the club based on various factors of team success if they choose to structure an agreement with that benefit. RSN contracts vary in size but may be generally related to a team's non-seasonal marketing assets. That is, teams with a large and successful franchise tend to enjoy larger RSN contracts in raw dollar amounts.

Devoted fans do not always choose to attend games at the stadium, instead, they may choose to watch the game on television. Moreover, research about customer demand for MLB game attendance found that fans' desire to watch a game may change during the game itself (Chung et al. 2016). This change happens as a result of the uncertainty of outcome hypothesis ( $\mathrm{UOH})$ whereby fan interest in the game increases as the game draws closer to an end with an unexpected winner or loser (Neale 1964). Thus, fans with no initial interest in a ballgame may still monitor game progress for an interesting twist at the end. It may not be feasible to get to the ballpark during an exciting game, but fans instead may choose to watch the end of the game on television. This scenario helps illustrate why a team's inseason marketing assets are related to local TV viewership. Seasonal success could generally result in higher levels of TV viewership.

The effectiveness of a team's marketing assets is likely indirectly related to team financial performance through local TV viewership for different reasons. Non-seasonal MA should have an influence on team financial performance via local TV because large metropolitan areas like New York and LA host the Yankees and the Dodgers who possess some of the largest RSN contracts. In-season MA might generate other portions of revenue through local TV, for example, if it results in higher than expected local TV viewership, and that contract rewards the MLB club financially for this success. For these reasons, we expect positive direct and indirect relationships will exist between MLB marketing assets, local TV viewership, and team financial performance:

H4a: Local TV viewership is positively related to club financials.

H4b: Local TV viewership partially mediates the positive relationship between non-seasonal marketing assets and team financials.

H4c: Local TV viewership partially mediates the positive relationship between in-season marketing assets and team financials.

\section{Twitter is changing the game}

Social media tools are an extension of a marketing program for sports teams (Williams et al. 2012). Others write that fan engagement with social media works to fulfill certain fan motivations, including passion, hope, esteem, and camaraderie (Satvros et al. 2014). If social media is a marketing program, then it likely classifies as a marketing asset under the unified theory of brand equity. However, if social media works to fulfill fan motivations, it could be classified instead as a form of stakeholder value. We adopt the view that Twitter acts as a bridge between marketing assets and stakeholder value but classify this social media forum as primarily a marketing asset. This classification is appropriate because Twitter is a communication tool in which information can be quickly shared among trusted networks of people who hold common interests, such as brand communities (McKee 2010).

Twitter following and usage for MLB rose dramatically over the past decade. Research about social media usage for baseball enthusiasts broadly categorized two different types of fans called lurkers and posters (Williams et al. 2012). Lurkers follow their team but do not post very often yet are more likely to attend games. Posters regularly comment on their social media feeds but exhibit fewer tendencies toward game attendance. The study concluded that posters exhibit increased team-related social media usage, yet they also are less likely to attend games than lurkers who post on social media more infrequently. These findings could indicate that devoted fans express their devotion over social media, but not necessarily with their wallets in the form of ticket purchases. Perhaps, instead, they choose to watch on the television.

However, other explanations for the differential game attendance habits of various types of social media followers are possible. One study compared the underlying structure and social network distances between Twitter fans of the New York Mets and fans of the New York Yankees. Yankees fans have many more followers on Twitter, but a far greater dispersion and social distance between one another than Mets fans (Watanabe et al. 2016). One possible explanation for this finding is that greater numbers of Yankees fans may be found outside the state of New York versus Mets fans who are more closely clustered. If true, it's possible that greater numbers of Yankees fans who live far away from their team geographically are simply unable to support their team at the ballpark, and instead do so via following on Twitter or watching on the television.

Two different explanations, based on prior research above, indicate that increased levels of social media usage and larger followings on Twitter could be associated with lower likelihoods for game attendance by fans. The first reason is that Twitter posters fulfill their fan motivations on 
social media, which would otherwise require a trip to the ballpark. The second reason is that teams with very large followings may also face significant geographic barriers in attending a game and instead root for their team on Twitter and perhaps watch the game on television. As Twitter fans become instantly aware of an interesting game from their feed, the uncertainty of outcome hypothesis holds that fans are more likely to want to watch and may look for a television in order to view the game. Lastly, Twitter likely functions as a traditional marketing asset, which can strengthen the existing relationships between fans and the financial performance of the team regardless of geographic location. This can happen, for example, by inducing the purchase of memorabilia or other MLB-related souvenirs. We hypothesize that the increase in the number of Twitter followers' changes some of the relationships within the MLB brand equity model:

H5a: Higher levels of Twitter followers will weaken the positive relationship between non-seasonal marketing assets and attendance.

H5b: Higher levels of Twitter followers will strengthen the positive relationship between in-season marketing assets and local TV viewership.

H5c: Higher levels of Twitter followers will strengthen the positive relationship between non-seasonal marketing assets and team financials.

\section{Methodology}

Publicly accessible secondary data from multiple sources were used in the analysis. Baseball attendance rose through 2012 (Beckman et al. 2012). For this reason, we chose to examine the years 2011 through 2018. At the time of this study, data for 2019 was not yet available. The data set consists of 30 MLB clubs over eight years resulting in an $\mathrm{N}=240$. A few cases of missing data were imputed. PLSSEM, as opposed to CB-SEM, is the appropriate structural equation modeling method for this study because it involves secondary data, is exploratory by design, and evaluates the potential for causal relationships between constructs (Hair et al. 2019b).

Annual population estimates according to the metropolitan statistical area, annual team offense, and baseball game attendance data are publicly available (Baseball Almanac n.d.; United States Census n.d.). We obtained baseball club financial information, including both revenue and valuation from reports available through Statista (2018). Revenue figures are modeled as season-ending data. Club valuation is measured at the beginning of each year and thus represents the valuation of prior year-end. For example, the $2018 \mathrm{club}$ value represents the results at the end of 2017. Other variables such as personal income, World Series wins by team and club age came from multiple sources (Baseball Reference n.d.; Major League Baseball n.d.; Statista n.d.). TV viewership data originally reported by Nielsen was gathered from two baseball data outlets and is reported each year by both Forbes.com and Sportsbusinessdaily.com (nd).

\section{Measures}

Variable selection and construct alignment were guided by the unified theory of brand equity and the literature review. We identify two major marketing assets, which include nonseasonal assets and in-season assets. Stakeholder value is measured in two ways, which include game attendance and local TV viewership. Additionally, we include a financial measure of firm value. This measure is critical to include because we are seeking to predict how marketing assets, stakeholder value, and firm value work together in the formation of brand equity within the business of baseball.

After the collection of numerous potential items to represent these constructs, we conducted separate principle component analyses for each construct with varimax rotation using SPSS 24.0. A measure of sampling adequacy was used in the variable retention decision. Variables with an anti-image correlation below 0.5 were eliminated oneby-one beginning with the lowest value until all retained variables were above 0.5 and $\mathrm{KMO}$ for the factor solution was above 0.6 (Hair et al. 2019a). Total variance extracted exceeds 0.6 for each construct. Eigenvalues are above 1 and above a parallel analysis of randomly generated eigenvalues from datasets with matching characteristics (Howard 2016). The results are shown below in Table 1. The full PCA results for every variable are listed in a web appendix.

\section{Non-seasonal marketing assets}

This construct is named NON SEASONAL. The seven items representing the latent construct include annual cumulative measures of the number of playoff appearances, pennant titles, division titles, world series wins, hall of fame players, the age of the baseball club in years, and the population of the MSA. The data sources are shown in the appendix, and the Cronbach's alpha for this measure is $\alpha=0.92$.

\section{In-season marketing assets}

This construct is named IN SEASON. The five items included in this latent construct represent team offense. They are the total annual number of hits, runs, doubles, at-bats, and sacrifice-fly outs. The data sources are shown 
Table 1 Principal components analysis

\begin{tabular}{|c|c|c|c|c|c|c|}
\hline Construct & Variable & Load & KMO & $\operatorname{VE}(\%)$ & Eigenvalue & Parallel \\
\hline \multirow[t]{7}{*}{ NON SEASONAL } & \# of Playoff appearances & 0.976 & \multirow[t]{7}{*}{$0.743 * * *$} & \multirow[t]{7}{*}{69.83} & \multirow[t]{7}{*}{4.888} & \multirow[t]{7}{*}{1.454} \\
\hline & \# of Penant Titles & 0.956 & & & & \\
\hline & \# of Hall of Fame Players & 0.880 & & & & \\
\hline & \# of Division Titles & 0.873 & & & & \\
\hline & Age of Baseball Club & 0.810 & & & & \\
\hline & \# of World Series Wins & 0.794 & & & & \\
\hline & MSA Population & 0.446 & & & & \\
\hline \multirow[t]{5}{*}{ IN SEASON } & \# of Hits & 0.916 & \multirow[t]{5}{*}{$0.768 * * *$} & \multirow[t]{5}{*}{61.33} & \multirow[t]{5}{*}{3.066} & \multirow[t]{5}{*}{1.485} \\
\hline & \# of Runs & 0.807 & & & & \\
\hline & \# of Doubles & 0.805 & & & & \\
\hline & \# of Total At Bats & 0.799 & & & & \\
\hline & \# of Sacrifice Flys & 0.540 & & & & \\
\hline \multirow[t]{4}{*}{ ATTEND } & Mean Game Attendance & 0.988 & \multirow[t]{4}{*}{$0.832 * * *$} & \multirow[t]{4}{*}{93.44} & \multirow[t]{4}{*}{3.738} & \multirow[t]{4}{*}{1.301} \\
\hline & Total Season Attendance & 0.988 & & & & \\
\hline & $\%$ of League Average & 0.954 & & & & \\
\hline & $\%$ of Seats Filled & 0.935 & & & & \\
\hline \multirow[t]{3}{*}{ LOCAL TV } & Local_Ranking & 0.848 & \multirow[t]{3}{*}{$0.633 * * *$} & \multirow[t]{3}{*}{63.20} & \multirow[t]{3}{*}{1.896} & \multirow[t]{3}{*}{1.101} \\
\hline & Neilsen rating & 0.833 & & & & \\
\hline & \# of Households & 0.694 & & & & \\
\hline \multirow[t]{3}{*}{ FINANCIALS } & Gross total revenue & 0.990 & \multirow[t]{3}{*}{$0.604 * * *$} & \multirow[t]{3}{*}{92.31} & \multirow[t]{3}{*}{2.769} & \multirow[t]{3}{*}{1.178} \\
\hline & Club valuation & 0.960 & & & & \\
\hline & Gate revenue & 0.931 & & & & \\
\hline
\end{tabular}

$* * * p<.001$ in the appendix, and the Cronbach's alpha for this measure is $\alpha=0.83$.

\section{Attendance}

This construct is labeled ATTEND. We model attendance as a latent variable using a blended set of four items, including total annual attendance, raw season average, percentage of filled seat capacity within the stadium, and percentage of league mean average attendance. The data sources are shown in the appendix, and the Cronbach's alpha for this measure is $\alpha=0.98$.

\section{Local TV viewership}

Local TV viewership is captured as a latent construct named LOCAL TV and includes three items measuring annual average local rank against other programs at the same time, the Nielsen rating points/share, and the average number of viewing households. This data is collected by Nielsen and reported through third party outlets, as listed in the appendix. The Cronbach's alpha for this measure is $\alpha=0.71$.

\section{Team financial performance}

We name this latent variable FINANCIALS and use three items. They are gross revenue, gate revenue, and club valuation. The data sources are shown in the appendix, and the Cronbach's alpha for this measure is $\alpha=0.96$.

\section{Twitter followers}

We include a single-item measure to capture the growing influence of social media measured by Twitter followers. The measure is modeled as a moderator of the relationships between marketing assets, stakeholder value, and firm performance. This data published by Statista.com measures the annual number of Twitter followers for each team in October.

\section{Measurement model}

PLS-SEM results are evaluated according to a two-step approach. (Sarstedt and Cheah 2019). Each step involves a series of assessments resulting in a confirmatory composite analysis (Hair et al. 2020). We assessed internal consistency reliability according to Cronbach's alpha and 
Table 2 Reliability and convergent validity

\begin{tabular}{|c|c|c|c|c|c|}
\hline Construct & Variable & $\mathrm{Cr} \mathrm{A}$ & $\mathrm{CR}$ & AVE & Loading \\
\hline \multirow[t]{7}{*}{ NON SEASONAL } & \# of Playoff Appearances & 0.92 & 0.94 & 0.69 & 0.980 \\
\hline & \# of Pennant Titles & & & & 0.960 \\
\hline & \# of Division Titles & & & & 0.849 \\
\hline & \# of World Series Wins & & & & 0.838 \\
\hline & \# of Hall of Fame Players & & & & 0.827 \\
\hline & Age of Baseball Club & & & & 0.744 \\
\hline & MSA Population & & & & 0.535 \\
\hline \multirow[t]{5}{*}{ IN SEASON } & \# of Hits & 0.83 & 0.88 & 0.61 & 0.893 \\
\hline & \# of Runs & & & & 0.859 \\
\hline & \# of Doubles & & & & 0.786 \\
\hline & \# of Total At Bats & & & & 0.741 \\
\hline & \# of Sacrifice Flys & & & & 0.575 \\
\hline \multirow[t]{4}{*}{ ATTEND } & Mean Game Attendance & 0.98 & 0.98 & 0.93 & 0.989 \\
\hline & Total Season Attendance & & & & 0.988 \\
\hline & $\%$ of League Average & & & & 0.955 \\
\hline & $\%$ of Seats Filled & & & & 0.934 \\
\hline \multirow[t]{3}{*}{ LOCAL TV } & \# of Households & 0.71 & 0.78 & 0.55 & 0.944 \\
\hline & Local_Ranking & & & & 0.642 \\
\hline & Nielsen Rating & & & & 0.588 \\
\hline \multirow[t]{3}{*}{ FINANCIALS } & Gross Total Revenue & 0.96 & 0.97 & 0.92 & 0.986 \\
\hline & Club Valuation & & & & 0.950 \\
\hline & Gate Revenue & & & & 0.943 \\
\hline
\end{tabular}

Table 3 Discriminant validity (HTMT)

\begin{tabular}{lllll}
\hline & $\begin{array}{l}\text { NON } \\
\text { SEA- } \\
\text { SONAL }\end{array}$ & IN SEASON & ATTEND & LOCAL TV \\
\hline IN SEASON & 0.14 & & & \\
ATTEND & 0.49 & 0.33 & & \\
LOCAL TV & 0.47 & 0.44 & 0.64 & \\
FINANCIALS & 0.74 & 0.25 & 0.68 & 0.53 \\
\hline
\end{tabular}

composite reliability. The measures shown in Table 2 were above the thresholds of 0.7 and 0.8 (Hair et al. 2019a). Evaluation of convergent validity for each construct is according to item loadings and AVE as reflected in Table 2. Eighteen of twenty-two loadings exceeded the recommendation of 0.708 , and all were significant at $p<0.001$. (Hair et al. 2017). Loadings between 0.4 and 0.7 should be retained if the deletion of the item will negatively affect the content validity of the construct (Hair et al. 2017). Additionally, the AVE for each construct exceeded the standard threshold of 0.5 (Hair et al. 2019a). We assessed discriminant validity with the heterotraitmonotrait method (HTMT). Table 3 shows that HTMT for each construct was well below the recommended level of 0.85 (Henseler et al. 2015).

\section{Structural model}

Figure 1 reflects the structural model with bootstrapped path coefficients, $p$ values, and $\mathrm{R}$ square for the endogenous constructs. The structural model was assessed for VIF, and all measures were below the recommended level of 3.0 (Hair et al. 2019a). Also reflected in Table 4 are the $\mathrm{R}$ square measures for the endogenous constructs. ATTEND has an $\mathrm{R}$ square of 0.32, and LOCAL TV has an R square of 0.34 . Both results explain a moderate amount of variance. Team FINANCIALS has an R square of 0.68 , which is approaching a strong amount of variance explained in the dependent variable (Hair et al. 2019b).

The results of the path analysis reveal that each hypothesized path was statistically significant $(p<0.001$, unless otherwise noted) except for the path between IN SEASON and FINANCIALS. The path between NON SEASONAL and ATTEND was 0.38 in support of H1a. The path between NON SEASONAL and LOCAL TV was 0.48 in support of H1b.The path between NON SEASONAL and FINANCIALS was 0.47 in support of H1c.The path between IN SEASON and ATTEND was 0.24 in support of H2a. The path between IN SEASON and LOCAL TV was 0.27 in support of H2b. The path between IN SEASON and FINANCIALS was 0.03 and not statistically significant; thus, H2c was not supported. This finding was unexpected but becomes clearer in conjunction with the results for $\mathrm{H} 3 \mathrm{~b}$ and $\mathrm{H} 4 \mathrm{~b}$. 
Fig. 1 Structural equation model

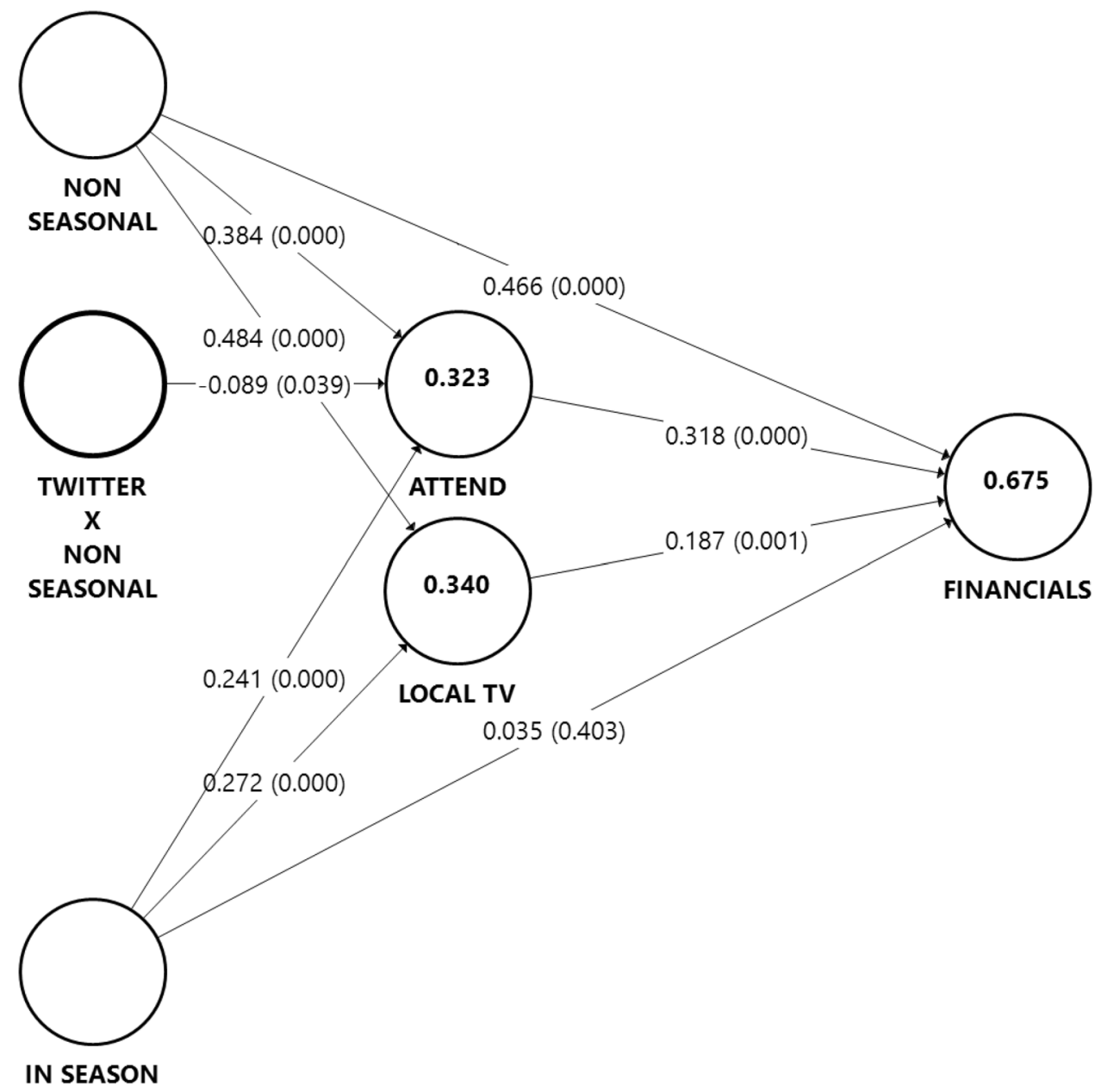

Table 4 Inner Model VIF and R square (Bootstrapped 5000 samples)

\begin{tabular}{llllll}
\hline & $\begin{array}{l}\text { NON SEA- } \\
\text { SONAL }\end{array}$ & IN SEASON & ATTEND & LOCAL TV & R Square \\
\hline IN SEASON & & & & & $0.323^{* * *}$ \\
ATTEND & 1.311 & 1.036 & & & $0.340^{* * *}$ \\
LOCAL TV & 1.014 & 1.014 & 1.776 & 1.888 & $0.675^{* * *}$ \\
FINANCIALS & 1.460 & 1.161 & 1.68 & \\
\hline
\end{tabular}

$* * * p<.001$

The path between ATTEND and FINANCIAL was 0.32 in support of H3a. The mediation results of ATTEND on the relationship between IN SEASON and FINANCIALS reflect a path of 0.08 in support of H3b. The mediation results of ATTEND on the relationship between NON SEASONAL and FINANCIAL reflect a path of 0.12 in support of $\mathrm{H} 3 \mathrm{c}$. The path between LOCAL TV and FINANCIAL was 0.19 in support of H4a. The mediation results of LOCAL TV on the relationship between IN SEASON and FINANCIAL reflect a path of $0.05(p<0.01)$ in support of $\mathrm{H} 4 \mathrm{~b}$. We can conclude that the relationship between IN SEASON team performance and team FINANCIALS is fully mediated by
ATTEND and LOCAL TV. Finally, the mediation results of LOCAL TV on the relationship between NON SEASONAL and FINANCIAL reflect a path of $0.09(p<0.01)$ in support of $\mathrm{H} 4 \mathrm{c}$. These results are summarized in Table 5.

\section{Moderation analysis}

The hypotheses related to the moderating effects of Twitter were tested using an orthogonal moderation approach, which effectively eliminates multicollinearity between the independent variables and the moderating variable (Hair et al. 2017). Each moderating effect is evaluated according 
Table 5 Structural Model Path Analysis (Bootstrapped 5000 samples)

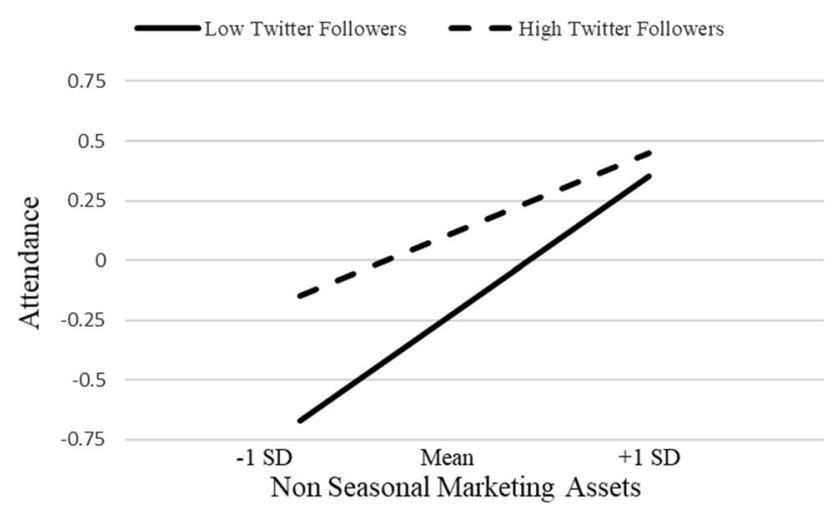

Fig. 2 Moderating effect of Twitter on the relationship between nonseasonal MA and attendance

to simple slope analysis whereby the mean relationships are evaluated at one standard deviation above and below the mean.

The moderating effect of Twitter followers on the relationship between NON SEASONAL and ATTEND is - 0.09 $(p<0.05)$ in support of H5a. Depicted graphically in Fig. 2, this moderating effect shows that higher levels of Twitter followers are associated with a weaker relationship between non-seasonal MA and game attendance. Whereas lower levels of Twitter followers reflect a stronger relationship between non-seasonal MA and game attendance.

The moderating effect of Twitter followers on the relationship between IN SEASON and LOCAL TV is 0.13 $(p<0.001)$ in support of H5b. Depicted graphically in

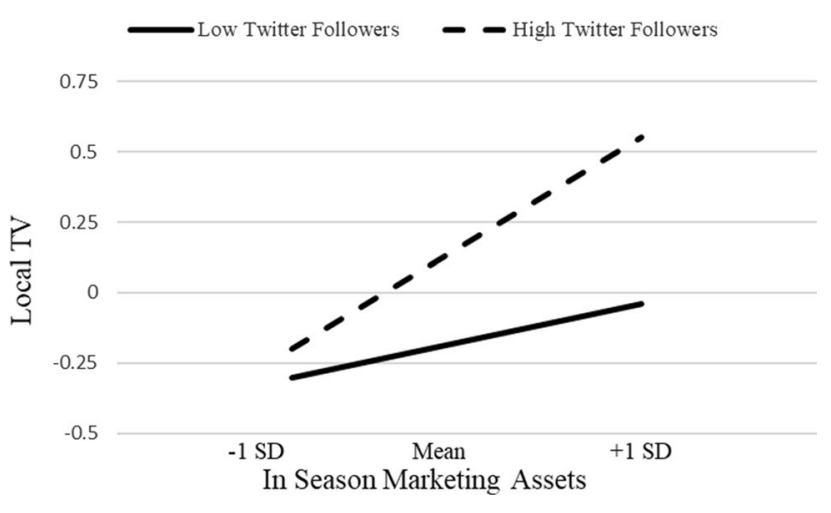

Fig. 3 Moderating effect of Twitter on the relationship between inseason MA and local TV viewership

Fig. 3, this moderating effect shows that higher levels of Twitter followers are associated with a stronger relationship between in-season MA and local TV viewership. Whereas lower levels of Twitter followers reflect a weaker relationship between in-season MA and local TV viewership.

The moderating effect of Twitter followers on the relationship between NON SEASONAL and FINANCIALS is $0.15(p<0.05)$ in support of H5c. Depicted graphically in Fig. 4, this moderating effect shows that higher levels of Twitter followers are associated with a stronger relationship between non-seasonal MA and team financials. Whereas lower levels of Twitter followers reflect a weaker relationship between non-seasonal MA and team financials. 


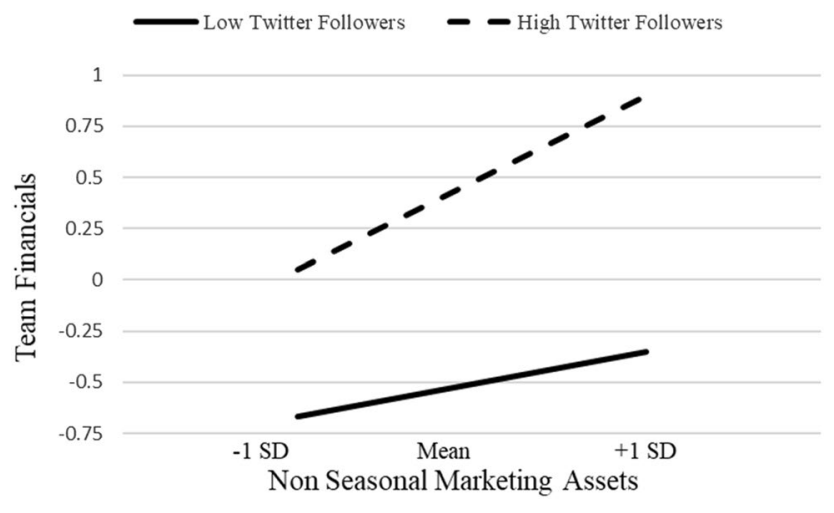

Fig. 4 Moderating effect of Twitter on the relationship between nonseasonal MA and team financials

\section{Longitudinal trend analysis}

The time-series nature of the data set allows for some trend analysis of the two measures associated with stakeholder value, which are attendance and local TV viewership. We additionally evaluate the trend of Twitter followers over the same time period. As shown in Fig. 5, for the years 2014 through 2019, attendance was flat and then declining while local TV viewership enjoyed a brief increase but has since begun to match the attendance decline. Meanwhile, Twitter followers steadily increased over the same time period. These basic longitudinal trends capture the shift in brand equity occurring in MLB, and together with the moderating effects, may begin to explain how sources of stakeholder value are changing.

\section{Discussion}

The focus of this research is the analysis of the decline in MLB ticket sales and game attendance within the larger framework of MLB brand equity. The research model empirically tests portions of a prior conceptualization of professional sports brand equity (Kerr and Gladden 2008). Moreover, we extend that conceptualization with the inclusion of Twitter followers and establish its moderating effect on various relationships. The brand equity model consists of two major categories of MLB marketing assets, their relationships with stakeholder value measured by attendance and local TV viewership, and firm value represented by team financials. Three findings discussed below include the replication and extension of prior research establishing two distinct marketing assets in MLB, the absence of any direct relationship between in-season marketing assets and team financial performance, and the adverse effect of rising numbers of Twitter followers weakening the relationship between non-seasonal MA and game attendance.

Research about MLB brand equity established the importance of two distinct marketing factors, one related to performance and one unrelated to performance (Feng and Yoon 2020). Those findings give some pause, however, because the sample in the study involved data from 2011 and 2012. Nevertheless, the findings in our model,

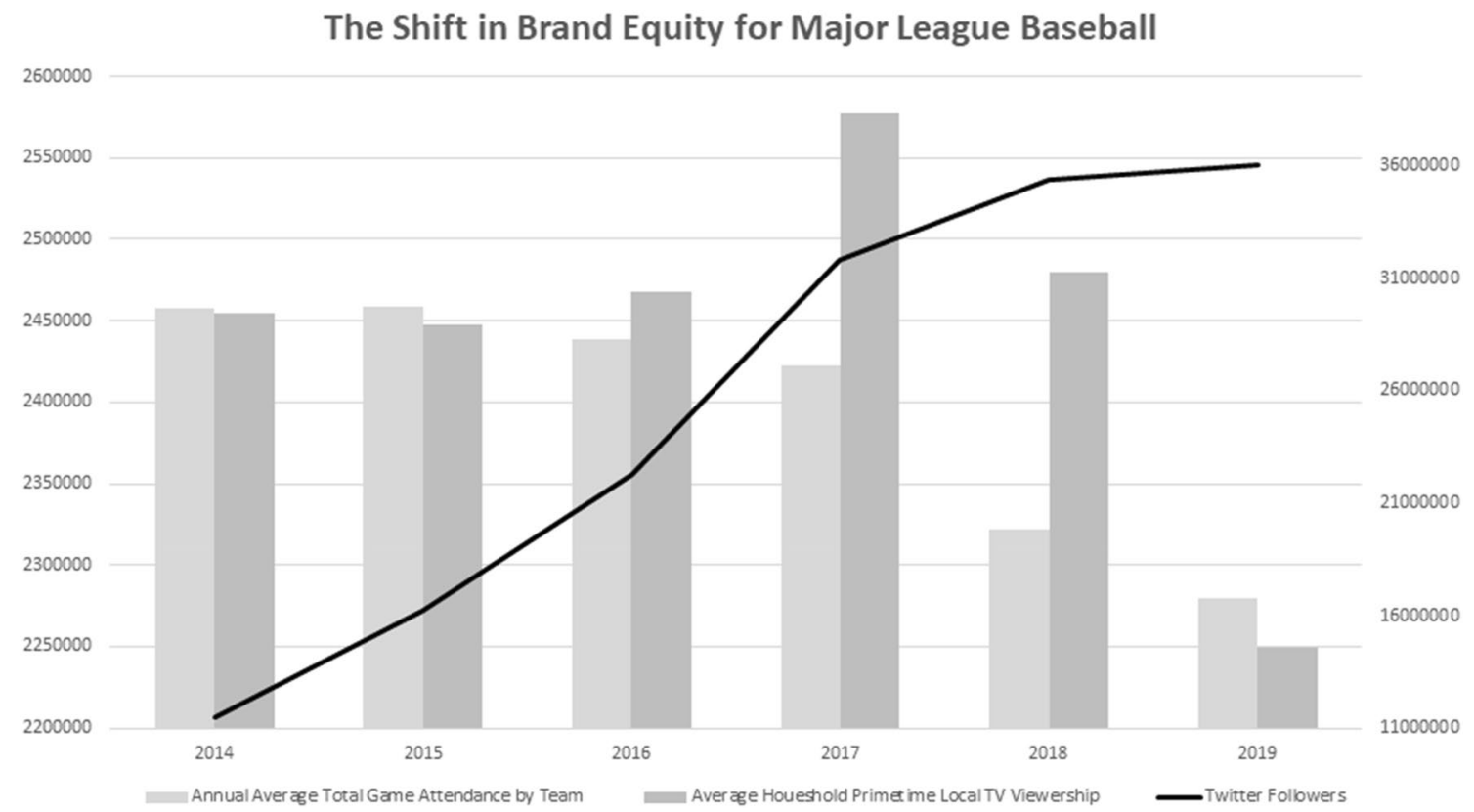

Fig. 5 Longitudinal trend analysis 
based on more recent data, advance the assertion that MLB teams should invest in and grow the effectiveness of both non-seasonal and in-season marketing assets because higher levels of MA are related to higher levels of stakeholder and firm value. Non-seasonal MA has a stronger relationship than in-season MA with attendance, local TV viewership, and firm value. Non-seasonal MA includes measures of long-term winning records such as division and pennant championships, along with World Series victories and the amount of Hall of Fame players. Thus, we can infer that a focus on consistent long-term success is more valuable to team brand equity than shortterm strategies aimed toward winning now.

The absence of a direct relationship between in-season marketing assets and team financial performance could indicate a decoupling of the relationship between on-field success and firm value. Taken to the extreme, these results could indicate that a single winning season may have no direct impact on the club's financial performance. Instead, the impact of that winning season is fully mediated by an increase in stakeholder value reflected in higher attendance and local TV viewership. Likewise, however, a single losing season may also have no direct impact on team financial performance. This finding could become a concern for MLB fans, if, for example, team ownership prioritizes firm value over stakeholder value by choosing not to address long-term on-field performance problems related to the team.

The third finding begins to address why ticket sales may be in decline as a result of a larger market shift in MLB brand equity. The rise in Twitter followers is associated with the adverse effect of a weaker relationship between non-seasonal MA and game attendance. Stated another way, teams with higher numbers of Twitter followers versus those with lower numbers reflect lower levels of attendance increases relative to the effectiveness of their non-seasonal marketing assets. Simultaneously, this same Twitter trend of higher followers is associated with a stronger relationship between in season MA and local TV viewership, and a stronger direct relationship between non-seasonal MA and team financial performance. Otherwise stated, teams with higher levels of Twitter followers reflect higher levels of local TV viewership given similar levels of effectiveness from in-season marketing assets. Likewise, teams with higher numbers of Twitter followers also reflect higher levels of team financial performance given similar levels of effectiveness in nonseasonal MA. In summary, teams with higher levels of Twitter followers have relatively lower levels of increases in game attendance, higher levels of local TV viewership, and higher levels of financial performance directly related to increases in their non-seasonal MA.

\section{Theoretical Implications}

The findings from this research offer two theoretical contributions. First, with research questioning the role theory plays in the face of increasing availability and analysis of data (Chandler 2015), we demonstrate that analysis of sports marketing data can build and support the development of the unified theory of brand equity (Davcik et al. 2015). We distinguish between the effects of two distinct marketing assets and their relative effects on financial performance as well as the mediating roles of attendance and local TV. As a result, we can begin to see the importance of the brand equity "mix" in the brand equity theory discussion, as evidenced by the analysis of sports marketing data.

Second, our study begins to answer the call for additional research about the interaction of the relationships at the intersection of marketing assets, stakeholder value, and financial performance (Davcik et al. 2015). While more work is needed to determine the relative strength of interactions between marketing assets, stakeholder value, and financial performance, our study may help explain how brand equity forms or changes over time. The unified theory of brand equity is just beginning to emerge, and every contribution brings the field one step closer to its validation.

\section{Sales and marketing implications}

The sales and marketing implications are best summarized in two ways. First, the effect sizes from in-season MA on attendance, local TV viewership, and team financial performance are all smaller relative to non-seasonal MA. Thus, non-seasonal MA are a more influential part of team brand equity than in-season MA. For this reason, MLB sales and marketing personnel should perhaps begin to look for ways to maintain fan interest in their teams through the emphasis of non-seasonal MA, rather than a focus on in-game team performance. However, some non-seasonal factors (i.e., \# of division titles, pennants, etc.) are based on cumulative, multi-season success. As such, team owners and managers can support sales and marketing efforts that promote brand equity growth through a balanced plan, which includes an emphasis on a long-term culture of winning (not necessarily a power offense), while still maintaining some level of in-season offensive excitement.

Second, while it may be important for marketing and sales teams to continue efforts toward activities that increase game attendance, such as giveaways and memorabilia, the results in this study demonstrate that some fans are making a choice to follow their favorite MLB teams in a different way, involving more Twitter and less in-person game attendance. Likewise, and according to $\mathrm{UOH}$, when games get interesting, these same Twitter followers seem to be drawn more strongly toward their local RSN broadcast to watch their 
team. While not specifically researched in this study, it is plausible that many of the Twitter followers represent those already in the brand community of their local team, and do not necessarily represent potential new fans who could become part of the brand community in the future.

Ticket sales initiatives, therefore, could be designed in ways that not only promote attendance but, more importantly, build upon non-seasonal sources of team brand equity. For example, promotions that develop a nostalgic habit of coming to the ballpark many times in a season for new customers may be more beneficial than sponsoring the traditional one-off bat-days or hat-days. Ballpark development partnerships focused on excellent fan experiences regardless of the actual results of any one game, such as the new park in Atlanta, GA, are another potential path to increase long-term brand equity.

Clearly, MLB will continue to increase revenue through future media contracts based on the recent agreement signed and set to begin in 2022 (Ozanian 2019). Thus, sales and marketing personnel should begin to think bigger. Technology is shrinking the world. As such, teams should not see themselves as geographically bound in the marketplace. Instead, it may be time for MLB sales and marketing managers to more fully shift toward additional sources of revenue by redirecting marketing asset management toward new technologies such as web-enabled interfaces and the coming opportunities available through augmented and virtual reality. In order to do so, MLB teams may need to focus on developing new competencies, for example, the development of a social CRM capability (Kim and Wang 2019). This study presents evidence that alternative channels of fan growth are changing the brand equity picture for MLB. This change is associated with a weaker relationship between a team's most important marketing asset and game attendance and could be a contributing factor in decreased ticket sales.

Lastly, the concept of satellite fans in professional sports was once just an idea (Kerr and Gladden 2008), but now may become an important area of new growth for MLB teams. In 2017, MLB released an early version of a virtual reality fan viewing experience called At-Bat VR (Petriello 2017). It is conceivable that fan viewership in the future will be increasingly virtual. When that time comes, teams should be ready to compete for fans anywhere in the world.

\section{Limitations and future research directions}

We note two limitations of this study. First, the use of secondary data is a limitation due to MLB being privately held and restricting access to more detailed information. We fully recognize that MLB has access to other variables of interest that could help deconstruct and provide understanding about additional sources of non-seasonal MA. From a sales perspective, one useful source of data from
MLB would be information about the structure of team incentives for ticket sales. Recent research highlighted the differential preferences of varying sales incentives among salespeople (Said 2019). In this view, are sales incentive structures appropriately aligned and related to critical marketing assets and attendance results? Within the realm of secondary data, social media channels other than Twitter, along with content analysis of MLB social media, is a readily available data-rich environment for additional insight.

A second limitation of this study is the annual analysis approach, which required some variables based on means and averages. Nevertheless, this model of MLB brand equity accounts for the decline in ticket sales and attendance based on secondary sports marketing data and sheds light on how the increase of an alternative marketing asset such as Twitter is related to a decline in game attendance.

Future research could look at individual teams' brand equity building activities as well as the business patterns of the owner. Do owners have a shareholder or stakeholder approach to the sport? Do they prioritize a long-term stakeholder approach to consistent winning or instead reflect a win-now-at-all-costs approach? With the substantial amounts of revenue reportedly coming from revenue sharing agreements and television contracts, to what degree does winning contribute to value creation? For example, if payroll and operating expenses are not a concern, ownership may be disincentivized, have a lowrisk profile, or lack the ambition to make marketing investments that could promote long-term brand equity. Additional future research could also involve an analysis of the game attendance effects within certain divisions or rivalries. In these situations, according to $\mathrm{UOH}$, game attendance may not be the result of the home team's seasonal success but instead attributed to the intrigue associated with the visiting team. Lastly, a future research project could consider the question of whether a consistent shortterm focus on seasonal offensive power has any positive long-term effect on brand equity.

In closing, we acknowledge the impact of COVID-19 on Major League Baseball. At the time of this writing, the pandemic has delayed the start of the 2020 season with an opening date yet to be determined. Even when the season starts, it is unclear whether fans will be permitted to attend games. Until the 2020 season begins, the ramifications on the sport from the pandemic are unknown. Future research will likely explore the impact on brand equity from this unprecedented event, and as such, the research model presented here is an ideal place to begin. We look forward to the time when America's favorite pastime will return, and we can once again "play ball!" 


\section{Compliance with ethical standards}

Conflict of interest On behalf of all authors, the corresponding author states that there is no conflict of interest.

\section{References}

Aaker, D.A. 1991. Managing Brand Equity. New York: The Free Press. Aaker, D.A. 1996. Measuring brand equity across products and markets. California Management Review 38 (3): 102-120.

Abreu, M. A., Spradley, B. D. (2016). The National Football League's Brand and Stadium Opportunities. The Sport Journal, 20.

Ahn, S.C., and Y.H. Lee. 2014. Major League Baseball attendance: Long-term analysis using factor models. Journal of Sports Economics 15 (5): 451-477.

Ambler, T., and P. Barwise. 1998. The trouble with brand valuation. Journal of Brand Management 5 (5): 367-377.

Baade, R.A., and L.J. Tiehen. 1990. An analysis of major League Baseball Attendance, 1969-1987. Journal of Sport and Social Issues 14 (1): 14-32.

Baseball Almanac. (n.d.). Major League Baseball Team History. https ://www.baseball-almanac.com/teammenu.shtml. Accessed 20 Aug 2019.

Baseball-reference.com. (n.d.) https://www.baseball-reference.com/ teams/. Accessed 20 Aug 2019.

Beckman, E.M., W. Cai, R.M. Esrock, and R.J. Lemke. 2012. Explaining game-to-game ticket sales for major league Baseball Games Over Time. Journal of Sports Economics 13 (5): 536-553.

Biscaia, R., A. Correia, S. Ross, A.F. Rosado, and J. Maroco. 2013. Spectator-based brand equity in professional soccer. Sport Marketing Quarterly 22: 20-32.

Bradbury, J.C. 2019. An empirical assessment: determinants of revenue in Sports Leagues. Economic Inquiry 57 (1): 121-140.

Bristow, D.N., and R.J. Sebastian. 2001. Holy cow! Wait 'til next year! A closer look at the brand loyalty of Chicago Cubs baseball fans. Journal of Consumer Marketing 18 (3): 256-275.

Brown, M. 2019. From Terrible Teams to Rising Costs: Why MLB Attendance Is Down Over 7\% Since 2015. Forbes, 4 October, https ://www.forbes.com/sites/maurybrown/2019/10/04/from-terribleteams-to-rising-costs-and-more-why-mlb-attendance-has-beendown-over-7-since-2015/\#5bc846c31a8d. Accessed 8 Oct 2019.

Chandler, D. 2015. A World Without Causation: Big data and the coming of age of posthumanism. Millennium 43 (3): 833-851.

Chatzipanagiotou, K., C. Veloutsou, and G. Christodoulides. 2016. Decoding the complexity of the consumer-based brand equity process. Journal of Business Research 69 (11): 5479-5486.

Chaudhuri, A., and M.B. Holbrook. 2001. The chain of effects from brand trust and brand affect to brand performance: The Role of Brand Loyalty. Journal of Marketing 65 (2): 81-93.

Chung, J., Y.H. Lee, and J.-H. Kang. 2016. Ex ante and ex post expectations of outcome uncertainty and Baseball Television Viewership. Journal of Sports Economics 17 (8): 790-812.

Davcik, N.S., R. Vinhas da Silva, and J.F. Hair. 2015. Towards a unified theory of brand equity: Conceptualizations, taxonomy and avenues for future research. Journal of Product and Brand Management 24 (1): 3-17.

deMause, N. 2019. What's the Matter with Baseball? Deadspin, 27 August, https://deadspin.com/whats-the-matter-with-baseball1837585854. Accessed 20 Sept 2019.

De Vries, N.J., and J. Carlson. 2014. Examining the drivers and brand performance implications of customer engagement with brands in the social media environment. Journal of Brand Management 21 (6): 495-515.
Domazlicky, B.R., and P.M. Kerr. 1990. Baseball attendance and the designated hitter. The American Economist 34 (1): 62-68.

Erevelles, S., N. Fukawa, and L. Swayne. 2016. Big data consumer analytics and the transformation of marketing. Journal of Business Research 69 (2): 897-904.

ESPN. 2012. The Steroids Era. 5 December, https://www.espn.com/ mlb/topics/_page/the-steroids-era. 26 Aug 2019.

Farquhar, P.H., and Y. Ijiri. 1993. A dialogue on momentum accounting for brand management. International Journal of Research in Marketing 10 (1): 77-92.

Feng, Y., and Y. Yoon. 2020. Dynamic brand evolution mechanism of professional sports teams: Empirical analysis using comprehensive major league baseball data. Journal of Brand Management 27 (3): 237-265.

Forbes. 2019. MLB's Most Valuable Television Deals. https://www. forbes.com/pictures/mlh45egkd/hanley-ramirez/\#377bb7a178d9. Accessed 24 Oct 2019.

Freeman, R.E. 1994. The politics of stakeholder theory: Some future directions. Business Ethics Quarterly 4 (4): 409-421.

Gupta, S., and D.R. Lehmann. 2006. Customer lifetime value and firm valuation. Journal of Relationship Marketing 5 (2-3): 87-110.

Hair Jr., J.F., W.C. Black, B.J. Babin, and R.E. Anderson. 2019a. Multivariate Data Analysis, 8th ed. Andover: Cengage Publishing.

Hair, J.F., M.C. Howard, and C. Nitzl. 2020. Assessing measurement model quality in PLS-SEM using confirmatory composite analysis. Journal of Business Research 109: 101-110.

Hair Jr., J.F., G.T. Hult, C.M. Ringle, and M. Sarstedt. 2017. A primer on partial least squares structural equation modeling (PLS-SEM). Thousand Oaks, CA: SAGE.

Hair, J.F., J.J. Risher, M. Sarstedt, and C.M. Ringle. 2019b. When to use and how to report the results of PLS-SEM. European Business Review 31 (1): 2-24.

Henseler, J., C.M. Ringle, and M. Sarstedt. 2015. A new criterion for assessing discriminant validity in variance-based structural equation modeling. Journal of the Academy of Marketing Science 43 (1): $115-135$

Hoeffler, S., and K.L. Keller. 2003. The marketing advantages of strong brands. Journal of Brand Management 10 (6): 421-445.

Howard, M.C. 2016. A review of exploratory factor analysis decisions and overview of current practices: What we are doing and how can we improve? International Journal of Human-Computer Interaction 32 (1): 51-62.

Hult, G.T.M., J.A. Mena, O.C. Ferrell, and L. Ferrell. 2011. Stakeholder marketing: A definition and conceptual framework. AMS Review 1 (1): 44-65.

Iacobucci, D., M. Petrescu, A. Krishen, and M. Bendixen. 2019. The state of marketing analytics in research and practice. Journal of Marketing Analytics 7 (3): 152-181.

Johnson, E.J., and J.E. Russo. 1984. Product Familiarity and Learning New Information. Journal of Consumer Research 11 (1): 542. https://doi.org/10.1086/208990.

Jones, R. 2005. Finding sources of brand value: Developing a stakeholder model of brand equity. Journal of Brand Management 13 (1): $10-32$.

Keller, K.L., and D.R. Lehmann. 2006. Brands and Branding: Research Findings and Future Priorities. Marketing Science 25 (6): 740-759.

Kelly, C.J. 2019. Strike Three: Baseball Is Dead. 3 February, https:// howtheyplay.com/team-sports/Baseball-A-Changing-Landscape. Accessed 24 Oct 2019.

Kent, R.J., and C.T. Allen. 1994. Competitive interference effects in consumer memory for advertising: The role of brand familiarity. Journal of Marketing 58 (3): 97-105.

Kerr, A.K., and J.M. Gladden. 2008. Extending the understanding of professional team brand equity to the global marketplace. International Journal of Sport Management and Marketing 3 (1/2): 58. 
Kim, H.G., and Z. Wang. 2019. Defining and measuring social customerrelationship management (CRM) capabilities. Journal of Marketing Analytics 7 (1): 40-50.

Koslosky, J.E. 2014. How the Steroid Era Saved Baseball. The Motley Fool, 14 January, https://www.fool.com/investing/gener al/2014/01/14/we-cant-ignore-the-steroid-era-it-just-might-have. aspx. Accessed 22 Oct 2019

Kunz, W.M. 2017. The rise of the local: The power of regional sports networks in the television marketplace. Journal of Sports Media 12 (1): 141-168.

Lane, V., and R. Jacobson. 1995. Stock market reactions to brand extension announcements: The effects of brand attitude and familiarity. Journal of Marketing 59 (1): 63-77.

Laplume, A.O., K. Sonpar, and R.A. Litz. 2008. Stakeholder theory: Reviewing a theory that moves us. Journal of Management 34 (6): 1152-1189.

Lee, Y.H. 2018. Common factors in Major League Baseball game attendance. Journal of Sports Economics 19 (4): 583-598.

Lemke, R.J., M. Leonard, and K. Tlhokwane. 2010. Estimating Attendance at Major League Baseball Games for the 2007 Season. Journal of Sports Economics 11 (3): 316-348.

Love, J. 2019. How Popular Is Baseball, Really? The New York Times, 22 October, https://www.nytimes.com/interactive/2019/10/22/sport s/baseball/baseball-popularity-worldseries.html. Accessed 22 Oct 2019.

Major League Baseball. 2019. Baseball History. https://mlb.mlb.com/ mlb/history/mlb_history_teams.jsp. Accessed 22 Oct 2019.

McGuire, J.B., A. Sundgren, and T. Schneeweis. 1988. Corporate social responsibility and firm financial performance. Academy of Management Journal 31 (4): 854-872.

Neale, W. 1964. The peculiar economics of professional sports. Quarterly Journal of Economics 78: 1-14.

Noll, R. 1974. Attendance and Price Setting. In Government and the Sports Business, ed. Roger Noll, 115-157. Washington, DC: The Brookings Institute.

Ozanian, Mike. 2019. Fox's MLB TV Deal Is Much Richer For Team Owners Than You Probably Think. Forbes, 23 April, https://www. forbes.com/sites/mikeozanian/2019/04/23/foxs-mlb-tv-deal-ismuch-richer-for-team-owners-than-you-probably-think/\#5f00a9e93a 00. Accessed 22 Oct 2019

Petriello, M. 2017. It's arrived: MLB At Bat VR makes debut. Major League Baseball.https://www.mlb.com/news/watch-live-virtual-reali ty-games-in-at-bat-vr-c230987420. Accessed 29 April 2020.

Rockerbie, D., and S. Easton. 2018. Revenue sharing in major league baseball: The moments that meant so much. International Journal of Financial Studies 6 (3): 71.

Said, E. 2019. Salespeople's reward preference methodological analysis. Journal of Marketing Analytics 7 (1): 24-39.

Sarstedt, M., and J. Cheah. 2019. Partial least squares structural equation modeling using SmartPLS: A software review. Journal of Marketing Analytics 7 (3): 196-202.

Shamsollahi, A., M. Amirshahi, and F. Ghaffari. 2017. Brand name recall: A study of the effects of word types, processing, and involvement levels. Journal of Marketing Communications 23 (3): 240-259.

Simon, C.J., and M.W. Sullivan. 1993. The measurement and determinants of brand equity: A financial approach. Marketing Science 12 (1): $28-52$

Sportsbusinessdaily.com (n.d.). https://www.sportsbusinessdaily.com/ Daily/Issues/2019/10/14/Media/. Accessed 12 Feb 2020.

Srivastava, R.K., L. Fahey, and H.K. Christensen. 2001. The resourcebased view and marketing: The role of market-based assets in gaining competitive advantage. Journal of Management 27 (6): 777-802.

Statista. (n.d.) Major League Baseball (Dossier No. did-10287-1). https:// www.statista.com/study/10287/major-league-baseball-statista-dossi er/. Accessed 1 Sept 2019.
Stavros, C., M.D. Meng, K. Westberg, and F. Farrelly. 2014. Understanding fan motivation for interacting on social media. Sport Management Review 17 (2014): 455-469.

Tainsky, S.A. 2008. Factors influencing demand in major league baseball: Steroid policy, discrimination, and uncertainty of outcome. $\mathrm{PhD}$ dissertation, University of Michigan, Ann Arbor, MI.

Terech, A., R.E. Bucklin, and D.G. Morrison. 2009. Consideration, choice, and classifying loyalty. Marketing Letters 20 (3): 209-225.

United States Census Bureau. (n.d.) https://www.census.gov/data/datatools.html. Accessed 22 Oct 2019.

Watanabe, Yan, and Soebbing, 2016. Consumer Interest in Major League Baseball: An Analytical Modeling of Twitter. Journal of Sport Management 30: 207-220.

Watkins, B.A. 2014. Revisiting the social identity-brand equity model: An application to professional sports. Journal of Sport Management 28 (4): 471-480.

Wedel, M., and P.K. Kannan. 2016. Marketing analytics for data-rich environments. Journal of Marketing 80 (6): 97-121.

Williams, J., R. Heiser, and S. Chin. 2012. Social media posters and lurkers: The impact on team identification and game attendance in minor league baseball. Journal of Direct, Data, and Digital Marketing Practice 13 (4): 295-310.

Yoo, B., N. Donthu, and S. Lee. 2000. An Examination of Selected Marketing Mix Elements and Brand Equity. Journal of the Academy of Marketing Science 28 (2): 195-211.

Zimmer, T.E. 2014. Estimating the World Series Gap Effect on Attendance. Choregia 10 (2): 21-31.

Publisher's Note Springer Nature remains neutral with regard to jurisdictional claims in published maps and institutional affiliations.

Adam C. Merkle is the purchasing agent at Bishop State Community College and an adjunct faculty member at the University of Mobile. He is a $\mathrm{PhD}$ candidate at the University of South Alabama with research interests in sales, ethics, marketing, analytics, and emerging technologies.

Catherine Hessick is a Lecturer of Marketing at James Madison University where she teaches undergraduate courses on business decision making, integrated marketing communications, and marketing foundations. In addition, she is a Ph.D. candidate at the University of South Alabama currently researching the ethical perspectives, moral disengagement, and unethical consumption behaviors of Generation Z. Her other research interests include advertising, humor, and branding.

Britton R. Leggett is a mathematics teacher at Neville High School (Monroe, LA) and a part-time adjunct at the University of Louisiana, Monroe. He is a Ph.D. candidate at the University of South Alabama with research interests in social media marketing, influencer marketing, and marketing analytics.

Larry Goehrig is the Operations Administrator at Nova Southeastern University's Huizenga College of Business. He is also an adjunct professor at Florida Memorial University for Finance courses. He is a Ph.D. candidate at the University of South Alabama with research interests in strategic management and finance. He was in real estate lending for twenty-one years and owned a lender for nine.

Kenneth O'Connor is a Marketing Ph.D. student at the University of South Alabama and an adjunct instructor of business at the University of West Florida. He gained much of his experience through managing his family's small kitchen and bath remodeling company in addition to managing other small and medium size construction companies. His research interests are loyalty, branding, entrepreneurship and family business. 